\title{
Membrana de látex natural de Hevea brasiliensis auxilia no processo de reparação tecidual em bovinos
}

\author{
[Natural latex rubber from Hevea brasiliensis aids tissue repair of bovine] \\ M. Zimmermann ${ }^{1}$, F.F. Mendes ${ }^{1}$, D.F. Rodrigues ${ }^{1}$, M.R. Faleiro ${ }^{1}$, \\ G.S. Campos $^{2}$, E.G. Araújo ${ }^{1}$ \\ ${ }^{1}$ Universidade Federal de Goiás - Goiânia, GO \\ ${ }^{2}$ Médica veterinária autônoma
}

\begin{abstract}
RESUMO
Feridas cutâneas em bovinos são um constante desafio clínico cirúrgico por desencadearem perdas econômicas bastante significativas. O látex proveniente da seiva da seringueira (Hevea brasiliensis) apresenta potencial terapêutico para incrementar o processo de reparação tecidual. Portanto, pretendeu-se com esse estudo avaliar o tipo de reação tecidual e os possíveis mecanismos de angiogênese desencadeados pelo implante de uma membrana de látex natural em bovinos. Para tal, foram utilizados seis bovinos da raça Nelore, submetidos ao implante subcutâneo experimental de três fragmentos de membranas de látex natural. Foram coletadas amostras de tecido e da membrana aos 15, 30 e 45 dias após a implantação, para avaliações histológicas, ultraestruturais por microscopia eletrônica de varredura e imunoistoquímicas com anticorpos antimarcador de macrófagos (MAC), CYR 61 e VEGF. O implante de látex proporcionou aumento da angiogênese e reparação tecidual em bovinos, não mediada pela expressão do VEGF e CYR 61.
\end{abstract}

Palavras-chave: angiogênese, bioatividade, cicatrização, borracha natural

\begin{abstract}
Cattle wounds are a constant surgical and clinical challenge, leading to important economical losses. The latex from the sap of the rubber tree (Hevea brasiliensis) has therapeutic potential to enhance tissue repair process. Therefore, we evaluated the type of tissue reaction and possible mechanisms of angiogenesis triggered by implanting natural latex rubber in bovine species. Six Nelore bovines were subjected to subcutaneous experimental implant of three fragments of natural rubber latex membranes. Tissue and rubber membrane samples were harvested at 15, 30 and 45 days implantation for histology, scanning electron microscopy and immunohistochemical evaluation with anti macrophage marker (MAC), anti CYR 61, anti VEGF antibodies. The latex membrane estimulates tissue reaction and repair and significant angiogenesis stimuli without activating CYR 61 and VEGF pathways.
\end{abstract}

Keywords: angiogenesis, bioactivity, natural rubber, wound repair

\section{INTRODUÇÃO}

As lesões envolvendo pele e anexos dos bovinos são um problema recorrente, que traz prejuízos para o animal à medida que afeta seu bem-estar, promovendo dor, infecções, dificuldade de locomoção, entre outros, além de trazer prejuízos econômicos para o produtor, tanto em criações de gado de leite como gado de corte (Lipinsky, 2008).

O látex natural da Hevea brasiliensis vem sendo estudado como um material bioativo, capaz de induzir reparação tecidual acelerada com o incremento da angiogênese no local de sua implantação (Rahimi e Mashak, 2013).

Recebido em 22 de maio de 2016

Aceito em 23 de fevereiro de 2017

E-mail: veterinariamarina@yahoo.com.br 
A utilização do látex natural proveniente da seiva da seringueira (Hevea brasiliensis) como biomaterial tem sido avaliada, por ser um material capaz de incitar a formação de novos vasos sanguíneos e reparar o tecido lesionado em menor tempo, estimulando a reação tecidual, o debridamento da ferida e a cicatrização (Maurício, 2006; Andrade, 2007; Zimmermann et al., 2008; Mendonça e Coutinho-Neto, 2009).

A neovascularização promovida pelo látex é estudada com afinco, por ser uma atividade de grande interesse para o incremento do processo de cicatrização (Frade et al., 2004; Mendonça e Coutinho-Neto, 2009; Dias et al., 2013).

O fator de crescimento endotelial VEGF induz a proliferação e a migração de células endoteliais, além de inibir a apoptose dessas durante a reparação tecidual (Taimeh et al., 2013). Por sua vez, a proteína CYR 61 estimula a expressão de VEGF nos fibroblastos, sendo capaz de incrementar a produção de fatores angiogênicos no sítio de cicatrização, assim como estimular a mitose e a quimiotaxia de células endoteliais e fibroblastos, desempenhando um papel importante na regulação da angiogênese e na remodelação da matriz do tecido de granulação durante o processo fisiológico de reparo tecidual (Brigstock, 2002; Kular et al., 2011; Lau, 2012). Dessa forma, o aumento da expressão de VEGF e CYR 61 pode ser um indicativo relevante para determinação do mecanismo de ação do látex natural no incremento do processo cicatricial, pois o aumento da expressão dessas proteínas indica aumento da produção e da atividade dessas no reparo tecidual (Kular et al., 2011; Taimeh et al., 2013).

Embora estudos em bovinos ainda sejam incipientes, há evidente potencial para que as membranas de látex tornem-se uma alternativa eficiente para o tratamento de lesões de pele, caso comprovadas suas ações biológicas nessa espécie. Dessa forma, o objetivo deste trabalho é verificar a reação tecidual induzida pela membrana de látex em bovinos, ou seja, sua bioatividade, o que pode vir a ser uma nova alternativa economicamente viável, de fácil aplicabilidade e maior agilidade na reparação de lesões de pele nessa espécie.

\section{MATERIAL E MÉTODOS}

O experimento foi conduzido de acordo com os princípios éticos de pesquisa em animais, após avaliação e aprovação pelo Comitê de Ética em Pesquisa da Universidade Federal de Goiás, protocolo $n^{\circ} 215 / 2009$.

Foi utilizado látex natural da seringueira Hevea brasiliensis, coletado horas antes da confecção do implante. Em laboratório, foi produzida a membrana de látex para uso como implante neste experimento, conforme modelo desenvolvido por Zimmermann et al. (2007).

Foram utilizados seis bovinos, da raça Nelore, machos, provenientes do plantel de animais do setor de produção da Escola de Veterinária e Zootecnia da Universidade Federal de Goiás (EVZ/UFG). Os animais estavam devidamente nutridos e saudáveis, com devido controle de doenças, endo e ectoparasitoses, e foram mantidos em regime de semiconfinamento.

Nos dias dos procedimentos cirúrgicos, foi feita a remoção de pelos do local e a antissepsia prévia. A contenção foi realizada em tronco do tipo trapézio, específico para bovinos. Em seguida, realizou-se a anestesia local com lidocaína sem vaso constritor, em bloqueio regional, na forma de retângulo em que estivesse contido o local a ser operado.

O procedimento cirúrgico foi realizado no dorso, do lado direito e do esquerdo. Para tal, foram feitas três incisões de $2 \mathrm{~cm}$, transversais à coluna vertebral e paravertebrais às vértebras L1 e L3, com uma distância de $5 \mathrm{~cm}$ entre elas. Realizouse, do lado direito, incisão de pele e subcutânea, confecção de um túnel por divulsão e inserção do implante de látex retangular, medindo $2 \times 3 \mathrm{~cm}$, fixação do fragmento com náilon 3-0, em padrão de sutura simples interrompida. Do lado esquerdo, foi realizado procedimento similar, sem a colocação do implante de látex, para servir como controle. A dermorrafia foi realizada com náilon 2-0, em padrão simples interrompido.

No pós-operatório, realizou-se limpeza e curativo no local. Ao redor da ferida cirúrgica, foi aplicado repelente aerosol. Realizou-se profilaxia antimicrobiana com penicilina $G$ benzatina (40.000UI/kg), por via intramuscular, e administrou-se dipirona, $25 \mathrm{mg} / \mathrm{kg}$, intravenoso, 
como analgésico, por 24 horas. Após 15 dias, foi realizada a retirada dos pontos.

A coleta das amostras ocorreu aos 15, 30 e 45 dias a partir da colocação do implante no dia zero. Para tal, foram removidas cirurgicamente biópsias com aproximadamente $2 \mathrm{~cm}^{2}$ de tecido circundante e do implante. Essas foram fixadas e armazenadas em frascos individuais, contendo formaldeído tamponado a $10 \%$, por 24 horas e, em seguida, removidas para álcool $70 \%$, onde permaneceram até seu processamento. Outra parte das amostras, bem como a membrana de látex, foi colocada em fixador Karnovisky por 24 horas, as quais foram trocadas para solução tampão cacodilato $0,1 \mathrm{~mol}$. Posteriormente foram acondicionadas em geladeira a $10^{\circ} \mathrm{C}$, para serem analisadas em microscopia eletrônica de varredura.

As características macroscópicas das feridas foram observadas semanalmente e classificadas, de acordo com a reação local, em ausente $=0$, discreta $=1$, moderada $=2$ ou acentuada $=3$.

Os fragmentos obtidos por biópsia foram processados de acordo com o método convencional de hematoxilina e eosina (HE). A análise histológica compreendeu uma descrição quantitativa dos infiltrados inflamatórios, realizada às cegas por patologista experiente, que classificou os infiltrados de acordo com os tipos celulares predominantes (mononucleares ou polimorfonucleares) e quanto à quantidade, classificando-os como discretos (infiltrado inflamatório ocupa até $25 \%$ do campo em aumento 40x), moderados (entre 25 e $50 \%$ ) ou acentuados (acima de 50\%).

A angiogênese foi quantificada de acordo com Andrade (2007). Para tal, as lâminas coradas com HE foram visualizadas no microscópio óptico, equipado com câmera e software para captura das imagens. Definiu-se o tamanho da imagem na objetiva de 40x e obtiveram-se cinco imagens de cinco campos aleatórios de cada lâmina. Para a contagem dos vasos neoformados, foi utilizado o plugin "Cell Counter" do software Image J®, versão 1.36.
O material para avaliação ultraestrutural por microscopia eletrônica de varredura (MEV) foi processado de acordo com as normas do Laboratório de Microscopia Eletrônica do Instituto de Ciências Biológicas da Universidade de Brasília (UnB). Inicialmente, o material foi pré-fixado, fixado e seco ao ponto crítico. Em seguida, foi metalizado com átomos de ouro em sua superfície, o que permitiu a visualização da amostra (Dedavid et al., 2007). As amostras de membranas de látex, material com alta capacidade de deformação, precisaram ser liofilizadas para evitar destruição da superfície quando da passagem pelo ponto crítico.

Para a avaliação imunoistoquímica, realizou-se recuperação antigênica em banho-maria, com citrato de sódio, por 30 minutos, para os antígenos VEGF e o marcador de macrófagos (MAC); já para o CYR 61, utilizou-se a panela Pascal, com citrato de sódio, em banho-maria. Foram utilizados os anticorpos primários antiVEGF (monoclonal de camundongo, Santa Cruz Biotechnology, Inc. California, USA), antimacrófagos (clone MAC 387 - monoclonal de camundongo, Santa Cruz Biotechnology, Inc. California, USA), por 30 minutos, e para o antiCYR61 (policlonal de cabra, Santa Cruz Biotechnology, Inc. California, USA) em panela de Pascal. Após a instilação dos anticorpos primários e respectivos secundários, a reação foi revelada com solução de diaminobenzidinaperoxidase por quatro minutos, seguida de contracoloração com hematoxilina, montagem e avaliação dos cortes ao microscópio de luz.

As marcações com os anticorpos CYR 61 (Fig. 1) e VEGF (Fig. 2) foram avaliadas de forma semiquantitativa quanto à intensidade de coloração, atribuindo-se os seguintes escores segundo a tonalidade de coloração pelo DAB: 0 = ausente; $1=$ discreta; $2=$ moderada; e 3= acentuada (Fujikawa et al., 2000).

Para quantificar os macrófagos marcados com o anticorpo específico, definiu-se o tamanho da imagem na objetiva de 40x e obtiveram-se cinco imagens de focos aleatórios de cada lâmina. Para a contagem, foi utilizado o plugin "Cell Conter" do software Image $\mathbf{J}^{\circledR}$, versão 1.36 (Andrade, 2007). 


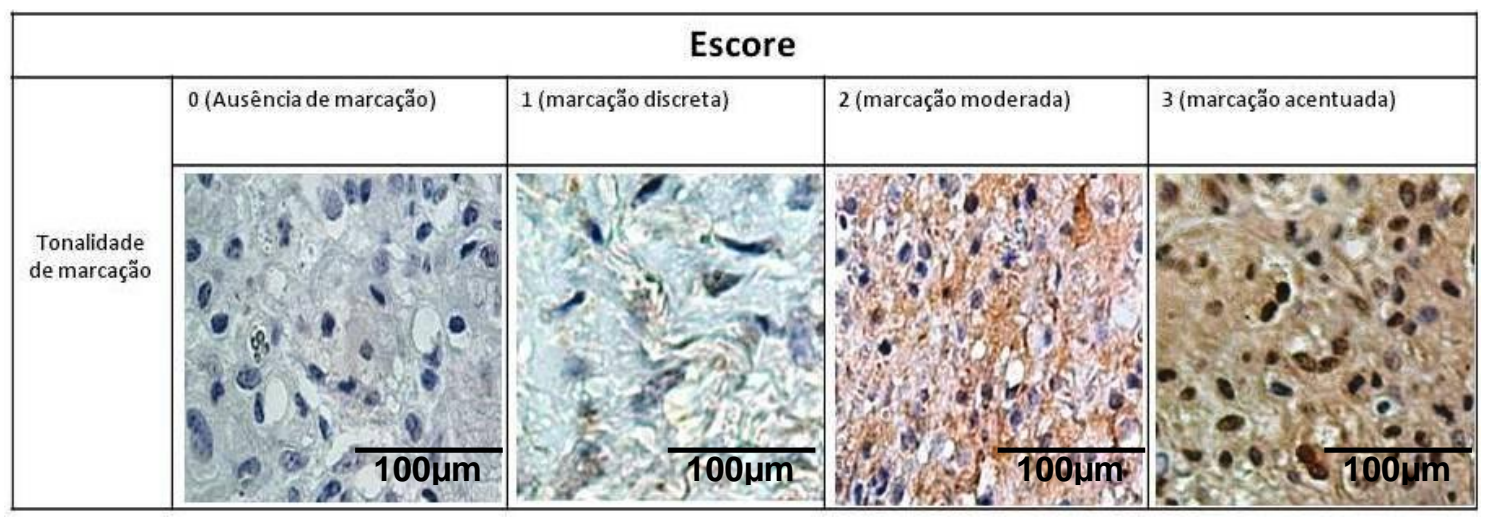

Figura 1. Escores de intensidade de marcação pelo anticorpo anti-CYR $61 \mathrm{em}$ tecido subcutâneo de bovinos submetidos à lesão experimental com e sem implante de látex.

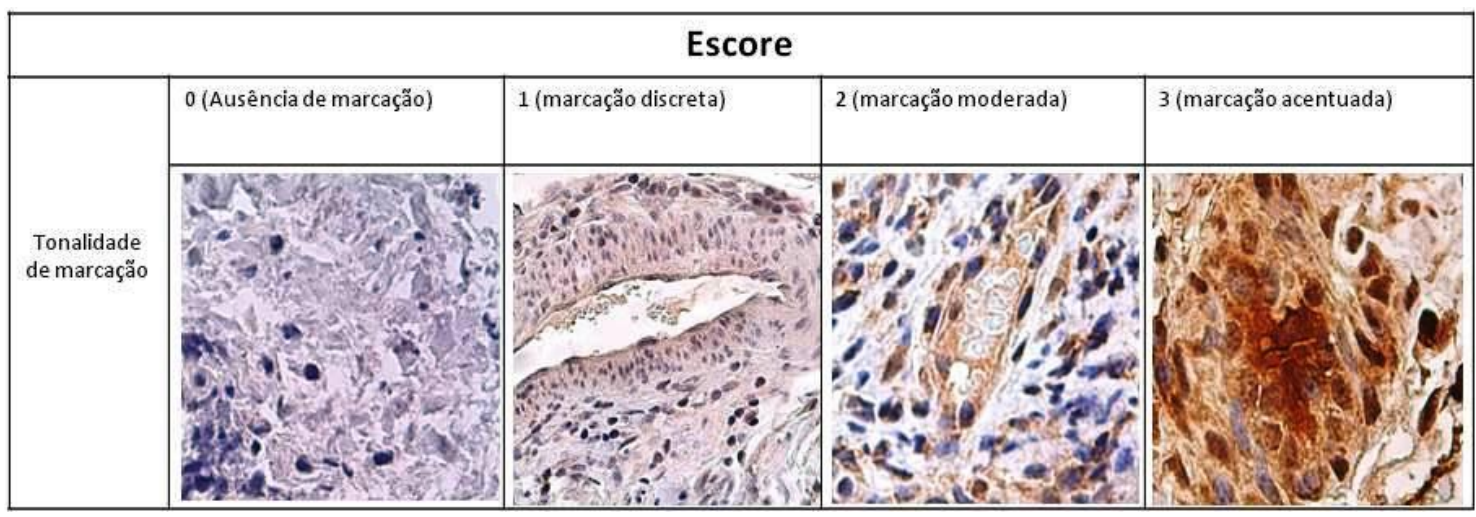

Figura 2. Escores de intensidade de marcação pelo anticorpo anti-VEGF em tecido subcutâneo de bovinos submetidos à lesão experimental com e sem implante de látex.

A análise estatística foi realizada pelo programa SPSS $^{\circledR}$ para Windows ${ }^{\circledR}$, versão 15.0. Para avaliar a influência dos grupos controle e látex em relação às variáveis, foram utilizados os testes qui-quadrado e Mann Whitney para dados não normais. Para avaliar a influência do látex ao longo do tempo, foi empregado o teste Friedman, e para confirmação da significância, foi analisada a diferença entre tempos de forma pareada, utilizando-se o teste Wilcoxon para dados não normais. Foi adotado como nível de significância o valor $5 \%(\mathrm{P}<0,05)$.

\section{RESULTADOS}

Os resultados das avaliações macroscópicas realizadas nos animais aos 15,30 e 45 dias de observação apresentaram ausência de sinais de inflamação em todos os animais do lado controle; já no lado com o implante de látex, aos 15 dias, três animais apresentaram moderada edemaciação, dois animais apresentaram tal característica de modo discreto, e um animal apresentou esse traço de maneira intensa. Aos 30 dias, dois animais apresentavam discreta edemaciação, um animal apresentava essa característica de forma intensa e três animais não apresentavam sinais de inflamação. Aos 45 dias, três animais apresentavam discreta edemaciação e apenas um bovino apresentava esse sinal de forma moderada, sendo esse ausente no restante. Um bovino apresentou formação de abscesso no local da inserção da membrana de látex até os 30 dias de análise, sendo necessária a drenagem do abscesso após a remoção da membrana.

A análise morfológica ultraestrutural da superfície coletada da membrana de látex por MEV evidenciou presença de substância amorfa e células sobre a membrana de látex. Não houve aderência da membrana no tecido adjacente. Passados 30 dias, essa rede tornou-se mais densa, e, aos 45 dias, esse tecido já se apresentava denso e espesso. No tecido adjacente à 
membrana de látex, foi possível visualizar células e tecido conjuntivo fibroso aos 15 dias (Fig. 3A), e, aos 30 dias, foi visualizado colágeno maduro e vasos sanguíneos (Fig. 3B).

Foi observado infiltrado inflamatório predominantemente mononuclear linfoplasmocitário na maioria dos animais, em todo o estudo. Entretanto, foram observados quatro animais no grupo látex com infiltrado polimorfonuclear neutrofílico aos 15 dias, reduzindo para três animais aos 30 dias e apenas um aos 45 dias. A presença de tecido conjuntivo fibroso foi acentuada nos animais do grupo látex quando comparados ao grupo controle e foi observada também acentuada neovascularização no grupo látex.
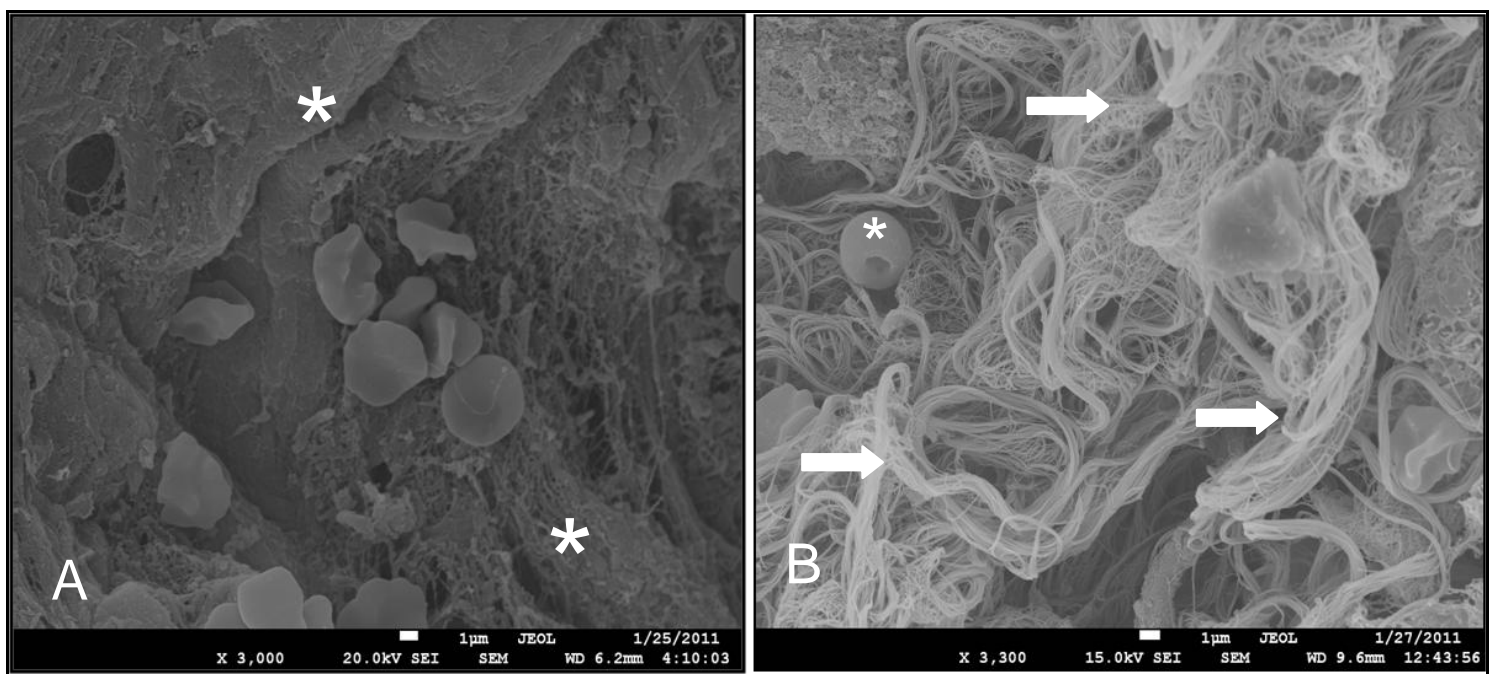

Figura 3. Eletromicrografias de varredura de fragmento retirado de tecido subcutâneo de bovino, em contato com a membrana de látex natural. A) Formação de tecido conjuntivo fibroso (asteriscos) adjacente à membrana de látex aos 15 dias de implantação. B) Presença de fibras colágenas (setas) e hemácia (asterisco) aos 30 dias de implantação. 3.000x.

Houve diferença significativa $(\mathrm{P}<0,05)$ na contagem do infiltrado inflamatório quando comparados os grupos látex e controle em todos os tempos avaliados (Tab. 1). Já com relação à intensidade do processo inflamatório no decorrer do experimento, não houve diferença significativa entre os momentos de observação aos 15,30 e 45 dias.

Com relação à contagem dos vasos sanguíneos neoformados, a quantidade no grupo látex foi significativamente maior que no grupo controle, para todos os tempos testados. Porém, quando comparados os resultados obtidos no grupo látex aos 30 e 45 dias, nota-se que não houve diferença significativa.
Os resultados referentes ao anticorpo MAC não foram significativos na análise estatística entre os grupos látex e controle em todos os tempos observados. Dessa forma, não foi constatado aumento de macrófagos ao longo do tempo de análise, em nenhum dos grupos.

Os resultados de expressão do VEGF não diferiram significativamente entre os grupos látex e controle em todos os tempos de análise. De modo similar, não houve incremento da expressão desse marcador ao longo do tempo no grupo látex. 
Tabela 1. Contagem e análise por meio do teste qui-quadrado do infiltrado inflamatório em bovinos aos 15,30 e 45 dias de implantação de membrana de látex e respectivo controle

\begin{tabular}{lccccc}
\hline Tempo de coleta e intensidade da reação inflamatória & Controle & $\%$ & Látex & $\%$ & P \\
\hline 15 dias & & & & & \\
Ausente & 1 & 16,7 & 0 & 0,0 & \\
Discreto & 4 & 66,7 & 0 & 0,0 & \\
Moderado & 1 & 16,7 & 5 & 83,3 & \\
Acentuado & 0 & 0,0 & 1 & 16,7 & \\
\hline Total & 6 & 100,0 & 6 & 100,0 & 0,034 \\
\hline
\end{tabular}

30 dias

\begin{tabular}{lccccc} 
Ausente & 1 & 16,7 & 0 & 0,0 \\
Discreto & 5 & 83,3 & 1 & 16,7 & \\
Moderado & 0 & 0,0 & 4 & 66,7 & \\
Acentuado & 0 & 0,0 & 1 & 16,7 & 0,034 \\
\hline Total & 6 & 100,0 & 6 & 100,0 & \\
\hline 45 dias & & & & & \\
Ausente & 2 & 33,3 & 0 & 0,0 & \\
Discreto & 3 & 50,0 & 0 & 0,0 & \\
Moderado & 0 & 0,0 & 4 & 66,7 & \\
Acentuado & 1 & 16,7 & 2 & 33,3 & \\
Total & 6 & 100,0 & 6 & 100,0 & 0,025 \\
\hline
\end{tabular}

\section{DISCUSSÃO}

O modelo empregado neste estudo de aplicação de membrana no subcutâneo de bovinos foi apropriado para analisar a capacidade dela em induzir reação tecidual e angiogênese, bem como avaliar seus aspectos imuno-histológicos. Kiriakides et al. (2001) relataram que esse modelo deve ser preferido quando não se quer avaliar influências externas e, sim, características fisiológicas do animal. Andrade (2007) obteve sucesso ao utilizar esse modelo para avaliar a influência da membrana de látex no subcutâneo de camundongos, da mesma forma que Zimmermann (2007) utilizou esse modelo em coelhos e cães, com o mesmo objetivo.

As alterações macroscópicas observadas nos animais com moderada e intensa edemaciação foram possivelmente relacionadas à presença de contaminação por microrganismos no local de inserção das membranas de látex, o que ocasionou uma infecção com inflamação aguda e infiltrado inflamatório polimorfonuclear neutrofílico. $\mathrm{O}$ fato de haver inflamação exacerbada apenas no grupo látex e não no controle pode estar relacionado ao estímulo do látex ao aumento da permeabilidade vascular (Maurício, 2006), que pode ter promovido um meio adequado para proliferação dos microrganismos inoculados no local. Neste estudo, não foi realizada antibioticoterapia, apenas profilaxia antimicrobiana. Portanto, os animais desenvolveram as infecções após 24 horas de cirurgia, sem cobertura medicamentosa, o que não deve acontecer na rotina clínica e evitaria o resultado apresentado.

Assim como observado neste experimento, Rabelo et al. (2005) também descreveram presença de infiltrado inflamatório mononuclear aos 30 dias de implante de látex. A inflamação foi classificada com escore acentuado em cinco animais avaliados no estudo descrito. De forma semelhante, a presença de infiltrado inflamatório também foi constatada por Mrué et al. (2004), sendo este moderado na primeira semana de avaliação e regredindo até a quarta semana.

Havia quantidade significativamente maior de vasos neoformados no grupo tratado com membrana de látex, comprovando a ação 
angiogênica do implante na espécie bovina, além de acentuada proliferação de tecido conjuntivo fibroso nesse mesmo grupo, o que auxilia na reparação tecidual. $\mathrm{O}$ processo de angiogênese induzido pelo látex da seringueira $H$. brasiliensis se deve às proteínas presentes nesse biomaterial (Agostini, 2009). Essa proteína foi isolada e caracterizada por Mendonça (2008) com o nome de FrHB1.2. Mesmo que tenha sido exaustivamente demonstrada a propriedade angiogênica do látex em diversas espécies (Mrué, 2000; Ereno, 2003; Frade et al., 2004; Mendonça, 2004; Maurício, 2006; Andrade, 2007; Dias et al., 2013), o mecanismo de ação ainda não está devidamente comprovado.

É importante ressaltar que, apesar do significativo incremento inicial, não houve influência da membrana de látex sobre a angiogênese ao compararem-se os tempos de coleta 30 e 45 dias. Isso indica que, como estratégia de uso terapêutico, é suficiente utilizar a membrana de látex na ferida até os 30 dias.

O aumento do número de vasos sanguíneos no grupo látex, quando comparado ao controle em todos os tempos avaliados, e a não modificação da expressão do VEGF são sugestivos de que não é por meio desse mecanismo que se dá a angiogênese. Resultado semelhante foi encontrado por Andrade (2007); entretanto, o autor sugere que a intensa atividade dos macrófagos possa ser a responsável pela neovascularização, opinião não corroborada pelos resultados do presente experimento, em que a marcação pelo MAC não evidenciou aumento do número de macrófagos em relação à cicatrização fisiológica do grupo controle.

Outro mecanismo fisiológico de estímulo à angiogênese é o aumento da expressão da proteína CYR 61, que é um membro da família das proteínas cuja expressão é elevada durante o crescimento de vasos, a cicatrização de feridas e diferenciação de condrócitos (Brigstock, 2002). Contudo, o envolvimento dessa via também não foi observado no presente estudo. Os resultados evidenciaram semelhança na expressão do CYR 61 nos dois grupos, tanto o controle como o látex. Desse modo, é provável que a proteína do látex não estimule a angiogênese e a reparação tecidual por meio do aumento da expressão de CYR 61.
Uma característica do implante de látex é a não aderência ao tecido em que foi justaposta, como foi visualizado por MEV neste estudo. Assim, é possível sua retirada sem alterar o tecido cicatricial criado por ela no momento da reparação (Paulo et al., 2005), como de fato ocorreu neste experimento. Uma explicação possível para a não adesão da membrana no leito receptor é a sua superfície, lisa e pouco aderente, além do estímulo ao aumento da permeabilidade vascular, fato esse experimentado por Maurício (2006), que provou que o látex natural da $H$. brasiliensis é responsável por essa característica de maior permeabilidade. No mesmo sentido, Frade et al. (2004) constataram a não adesão da membrana de látex no leito da úlcera, com intensa exsudação.

Os resultados evidenciaram que a nova membrana de látex é bioativa, participa da angiogênese e promove a reparação tecidual em bovinos, por mecanismos celulares que, por serem diferentes das vias de transdução de sinal do VEGF e CYR 61 aqui testados, ainda necessitam ser mais bem estudados.

\section{CONCLUSÕES}

A nova membrana de látex promove incremento da resposta inflamatória, principalmente na fase inicial do processo em bovinos, e estimula a angiogênese, de maneira significativa, na fase inicial, de forma independente de VEGF e CYR 61.

\section{REFERÊNCIAS}

AGOSTINI, D.L.S. Caracterização dos constituintes do látex e da borracha natural que estimulam a angiogênese. 2009. 101f. Dissertação (Mestrado em Ciência e Tecnologia de Materiais) - Faculdade de Ciências e Tecnologia, Universidade Estadual Paulista, Presidente Prudente, São Paulo, SP.

ANDRADE, T.A.M. Atividade da biomembrana de látex natural da seringueira (Hevea brasiliensis) na neoformação tecidual em camundongos. 2007. 138f. Dissertação (Mestrado em Clínica Médica) Faculdade de Medicina, Universidade de São Paulo, Ribeirão Preto, SP.

BRIGSTOCK, D.R. Regulation of angiogenesis and endothelial cell function by connective tissue growth factor (CTGF) and cysteine-rich 61 (CYR 61). Angiogenesis, v.5, p.153-165, 2002. 
DEDAVID, A.B.; GOMES, C.I.; MACHADO, G. Microscopia eletrônica de varredura. Aplicações e preparação de amostras. Materiais poliméricos, metálicos e semicondutores. EDIPUCRS, v.1, p.1-54, 2007.

DIAS, F.J.; ISSA, J.P.M.; IYOMASA, M.M. et al. Application of a low-level laser therapy and the purified protein from natural latex (Hevea brasiliensis) in the controlled crush injury of the sciatic nerve of rats: a morphological, quantitative, and ultrastructural study. BioMed. Res. Int., v.2013, p.1-11, 2013.

ERENO, D. Curativo de borracha. Rev. Pesqui. Fapesp, v.6, p.66-69, 2003. Disponível em: <http://www.fapesp.org.br/revistapesquisa.fapesp.br>. Acessado em: 12 nov. 2011.

FRADE, M.; CURSI, I.; ANDRADE, F. et al. Management of diabetc skin woulds with a natural latex biomembrane. Med. Cutánea Ibero-Lat. Am., v.32, p.157-162, 2004.

FUJIKAWA, D.G.; SHINMEI, S.S.; CAI, B. Kainic acid-induced seizures produce necrotic, not apoptotic, neurons with internucleosomal DNA cleavage: implications for programmed cell death mechanisms. Neuroscience, v.98, p.41-53, 2000.

KULAR, L.; PAKRADOUNI, J.; KITABGI, P. et al. The CCN family: a new class of inflammation modulators? Biochimie, v.93, p.377-388, 2011.

KYRIAKIDES, T.R.; ZHU, Y.H.; YANG, Z. et al. Altered extracellular matrix remodeling and angiogenesis in sponge granulomas of thombospondin 2-null mice. Am. J. Pathol., v.159, p.1255-1262, 2001.

LAU, L.F. CCN1 and CCN2: blood brothers in angiogenic action. J. Cell Commun. Signal., v.6, p.121-123, 2012.

LIPINSKI, L.C. Comparação da atividade cicatrizante na pele bovina entre fitoterápicos de uso tópico. 2008. 63f. Dissertação (Mestrado em Ciências Veterinárias) - Faculdade de Medicina Veterinária, Universidade Federal do Paraná, Curitiba, PR.

MAURÍCIO, V. Aceleração do reparo tissular induzido por uma fração angiogênica purificada do látex natural da seringueira Hevea brasiliensis. 2006. 111f. Dissertação (Mestrado em Medicina) Faculdade de Medicina, Universidade de São Paulo, Ribeirão Preto, SP.
MENDONÇA, R.J. Caracterização biológica de uma fração angiogênica do látex natural da seringueira Hevea brasiliensis. 2004. 85f. Dissertação (Mestrado em Ciências) - Departamento de Bioquímica e Imunologia, Universidade de São Paulo, Ribeirão Preto, SP.

MENDONÇA, R.J. Purificação e caracterização de uma proteína angiogênica, indutora de fibroplasia e cicatrizante presente no látex natural da seringueira Hevea brasiliensis. 2008. 137f. Tese (Doutorado em Ciências) - Faculdade de Medicina, Universidade de São Paulo, Ribeirão Preto, SP.

MENDONÇA, R.J.; COUTINHO-NETTO, J. Aspectos celulares da cicatrização. Anais Bras. Dermatol., v.84, p.257-262, 2009.

MRUÉ, F.; COUTINHONETTO, J.; CENEVIVAA, R. et al. Evaluation of the biocompatibility of a new biomembrane. Mater. Res., v.7, p.277-283, 2004.

PAULO, N.M.; SILVA, M.A.M.; CONCEIÇÃO, M. Biomembrana de látex natural (Hevea brasiliensis) com polilisina a $0,1 \%$ para herniorrafia perineal em um cão. Acta Sci. Vet., v.33, p.79-82, 2005

RABELO, R.E.; SANT'ANA, F.J.F.; PAULO, N.M. et al. Emprego do compósito látex, poliamida e polilisina a $0,1 \%$ na correção cirúrgica de hérnias umbilicais recidivantes em bovinos leiteiros. Acta Sci. Vet., v.33, p.169-175, 2005.

RAHIMI, A.; MASHAK, A. Review on rubbers in medicine: natural, silicone and polyurethane rubbers. Plast. Rubber Compos., v.42, p.223-230, 2013.

TAIMEH, Z.; LOUGHRAN, J.; BIRKS, E.J.; BOLLI, $\mathrm{R}$. Vascular endothelial growth factor in heart failure. Nat. Rev. Cardiol., v.10, p.519-530, 2013.

ZIMMERMANN, M. A membrana de látex como implante para correção de defeitos musculares em cães e coelhos. 2007. 78f. Dissertação (Mestrado em Cirurgia Veterinária) - Faculdade de Medicina Veterinária, Universidade Federal de Santa Maria, Rio Grande do Sul, RS.

ZIMMERMANN, M.; RAISER, A.G.; BARBOSA, A.L.T. et al. Teste de biocompatibilidade e resistência de membranas de látex em cães. Ciênc. Rural, v.37, p.1719-1723, 2007.

ZIMMERMANN, M.; RAISER, A.G.; BRAGA, F.V.A. et al. Membranas de látex natural na herniorrafia diafragmática experimental em cães. Arq. Bras. Med. Vet. Zootec., v.60, p.1476-1483, 2008. 